\title{
A pituitary mass as consequence of a decimal error in levothyroxine dose
}

\author{
Kristin Clemens MD, Stan Van Uum MD PhD
}

See also practice article by Ramadhan and Tamilia on page 205 and at www.cmaj.ca/lookup/doi/10.1503/cmaj.110994

Competing interests: Stan Van Uum sits on advisory boards for Novartis and Abbott Canada; he has received grants from Novartis and Genzyme; he has received payment for lectures and the development of educational presentations from Novartis and Eli Lilly; and he has been reimbursed for travel expenses by Novartis. No other competing interests were declared.

This article has been peer reviewed.

Affiliation: From the Department of Medicine, Schulich School of Medicine and Dentistry, University of Western Ontario, London, Ont.

\section{Correspondence to:}

Dr. Stan Van Uum, stan.vanuum@sjhc.london .on.ca

CMAJ 2012. DOI:10.1503 /cmaj.111883

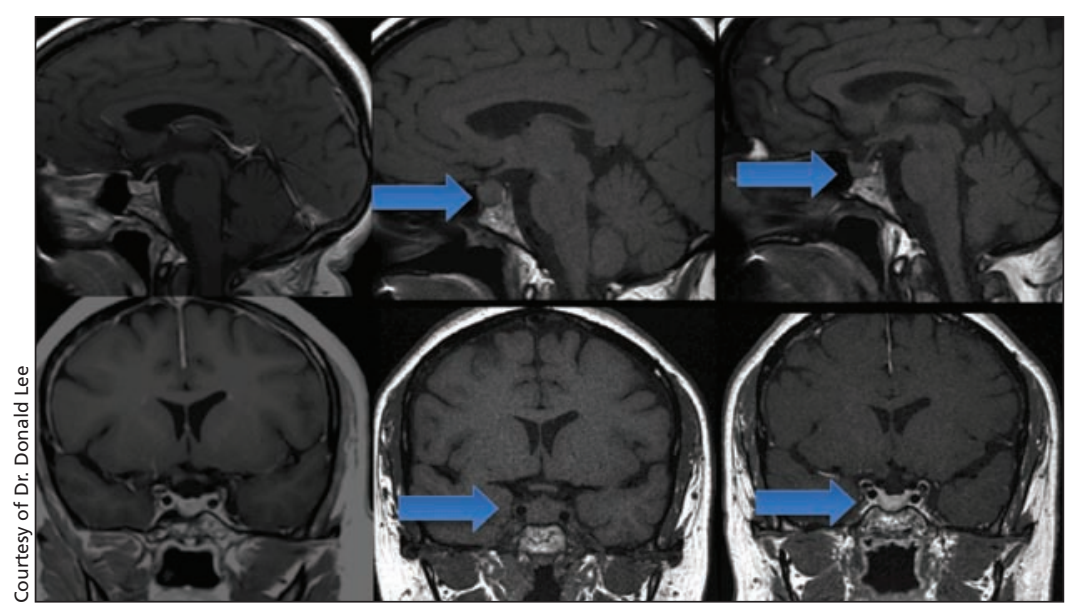

Figure 1: Magnetic resonance images showing sagittal and coronal sections of the head of a 37-year-old woman at baseline (left panel); at presentation, when her pituitary gland was homogenously enlarged (arrows) owing to severe clinical hypothyroidism (middle panel); and after her levothyroxine dosage was corrected (right panel), when the pituitary mass had decreased in size (arrows).
2.5 [normal 3.0-6.5] pmol/L, free thyroxine level 5 [normal 10-24] pmol/L and prolactin level 79 [normal 3-29] $\mu \mathrm{g} / \mathrm{L})$. Magnetic resonance imaging (MRI) showed that the patient's pituitary gland was homogeneously enlarged, suggesting hyperplasia (Figure 1). We increased the dosage of levothyroxine to $0.3 \mathrm{mg}$ daily. Over the next few months, the patient's symptoms improved and follow-up laboratory tests showed more normal results. A follow-up MRI showed that the pituitary mass had decreased in size (Figure 1). We subseqently learned that when our patient's dosage of levothyroxine had been increased to $0.25 \mathrm{mg}$ daily, her pharmacy had dispensed $0.025 \mathrm{mg}$ daily rather than the prescribed dose.

Severe primary hypothyroidism results in pituitary hyperplasia when thyrotropin-releasing hormone overstimulates pituitary thyrotrophs. ${ }^{1}$ Prolactin may also be secreted. Because imaging studies may not reliably differentiate between hyperplasia and macroadenomas, ${ }^{1}$ adequate clinical assessment is critical. Appropriate levothyroxine therapy may resolve the hyperplasia, thus avoiding the need for surgical intervention.

Poor adherence, malabsorption and drug interactions are important causes of subtherapeutic responses to pharmacologic treatment. However, errors in dosing should also be considered, particularly when doses are dispensed in less than one unit. ${ }^{2}$ To avoid such errors, zeroes should be routinely placed before a decimal and drug units should be clearly written. Electronic prescriptions may improve legibility and facilitate drug calculations. ${ }^{2,3}$

\section{References}

1. Simsek E, Simsek T, Savas-Erdeve S, et al. Pituitary hyperplasia mimicking pituitary macroadenoma in two adolescent patients with long-standing primary hypothyroidism: case reports and review of the literature. Turk J Pediatr 2009;51:624-30.

2. Lesar T. Tenfold medication dose prescribing errors. Ann Pharmacother 2002;36:1833-9.

3. Levine JM. A quality improvement study: medication error leading to thyrotoxicosis and death. J Am Med Dir Assoc 2004;5:410-13. 